\title{
O CONHECIMENTO DE MUNDO PARTILHADO NA PRODUÇÃO DOS SENTIDOS
}

\author{
Hilda Cristina Restaino ${ }^{1}$
}

\begin{abstract}
Resumo: $O$ presente artigo aborda o conhecimento de mundo partilhado, procurando mostrar que, muitas vezes, o aluno não constrói o sentido adequado de um texto, porque os referentes apresentados não são, na verdade, partilhados. Está sustentado na concepção sociocognitivista interacional e em análise de atividade de leitura, feita com alunos do $6^{\circ}$ ano do Ensino Fundamental, que apresentam problemas associados ao desconhecimento de saberes que se supõem partilhados. Propõe o uso de estratégias antecedentes à leitura para amenizar o problema.
\end{abstract}

Palavras-chave: Conhecimento de mundo partilhado, produção de sentido, mal-entendido.

\section{Introdução}

Este trabalho objetiva verificar como sutilezas dos textos passam desapercebidas ao aluno porque lhe falta conhecimentos de mundo que, por consenso, acredita-se serem partilhados.

O conhecimento de mundo partilhado é o primeiro aspecto do texto que deve ser trabalhado com o aluno para que ele construa os sentidos do enunciado e, posteriormente, o interprete, participando, assim, do jogo comunicativo.

Nas aulas de leitura, percebe-se que, muitas vezes, o aluno constrói equivocadamente ou deixa de construir os sentidos do texto, porque não ficam claras para ele informações que, aparentemente, deveriam ser conhecimentos partilhados de mundo. Assim, o tema será tratado por meio da concepção sociocognivista interacional, procurando mostrar que aquilo que, muitas vezes, parece velho, na verdade, é novo ao aluno.

Para exemplificar o fato apresentar-se-á uma atividade de leitura, realizada em sala de aula com alunos do $6^{\circ}$ ano do ensino fundamental. Essa atividade apresentou problemas na produção de sentidos porque cada um armazena os conhecimentos na memória considerando suas experiências, sendo pouco provável um grupo partilhar exatamente o mesmo conhecimento de mundo.

\section{O conhecimento de mundo partilhado}

O texto, atualmente, é visto como um evento lingüístico, no qual fatores cognitivos e sociais interligam-se, ou seja, ocorre um jogo em que enunciador e coenunciador agem juntos, equilibrando seus conhecimentos, a fim de atuarem em um

\footnotetext{
${ }^{1}$ Pós-graduanda em Língua Portuguesa da PUC-SP. Professora da rede pública do Município e do Estado de São Paulo.
} 
jogo interacional, no qual os participantes dispõem de saberes lingüísticos, enciclopédicos, sociointeracionais e procedimentos, mais ou menos, compartilhados.

Quando um leitor/ouvinte ativa conhecimentos, arquivados em sua memória, tanto semântica quanto episódica, sua intenção é buscar sentido no que foi dito ou escrito para desencadear uma representação textual que possibilite a compreensão, pois, segundo Grice(1975), há um Princípio de Cooperação que alicerça a busca de sentidos. Cabe ao enunciador empenhar-se para ser compreendido e, no seu turno, cabe ao co-enunciador, também, participar do mesmo empenho.

Para Koch (2002), o enunciador, muitas vezes, pressupõe conhecimentos do coenunciador - Princípio de Economia -, por isso mesmo, não os explicita no texto, deixando setas que o leitor/ouvinte deve seguir a fim de produzir os sentidos. No entanto, o que ocorre quando esse conhecimento, na verdade, não é compartilhado? Daí surgem os mal-entendidos. O procedimento do co-enunciador é voltar e buscar um novo caminho para construir uma representação coerente do referente trabalhado; assim, a compreensão e a coerência são subjetivas, pois dependem dos modelos cognitivos, ou seja, da capacidade do co-enunciador reativar um conhecimento. Como afirma Geraldi (1997: 18 ), a compreensão já não é mera decodificação e a reflexão sobre os próprios recursos utilizados e essa reflexão, acontece graças à interação que deve ocorrer entre o sujeito-produtor e o ouvinte/leitor . Para o autor, a interação está associada à experiência vivida, ou seja, aos modelos cognitivos arquivados na memória.

Por isso, para um texto ser coerente deve haver nele um equilíbrio entre informação dada e informação nova, pois um texto que só contenha informações desconhecidas é inteligível, da mesma forma, um texto que apresenta grande quantidade de informações conhecidas é redundante e não cumpre o propósito comunicativo de informar.

Em sala de aula percebe-se que o mal-entendido está relacionado, principalmente, ao desconhecimento do aluno de saberes tanto lingüísticos quanto episódicos que se acredita serem compartilhados, na verdade, são muitas informações novas.

Nesse ponto, observa-se que o professor, por julgar o tema óbvio, não volta para esclarecer a dúvida, ou seja, o assunto se mostra, muitas vezes, tão evidente para a compreensão do professor que esse julga desnecessária uma retomada; assim, o insucesso do aluno é atribuído a sua falta de atenção aos implícitos (pistas) deixados pelo enunciador ao longo do texto.

Além disso, estamos a todo momento reorganizando as representações que fazemos do mundo e, nessas reorganizações, às vezes, podem ficar lacunas que precisam ser preenchidas com algum dado simples que passa desapercebido ao aluno, porque ele está na fase de coleta de dados, ainda, não é um leitor totalmente pronto e precisa de ajuda para descartar ou guardar informações.

Para Koch (id.), a memória processa as informações em três fases: a da estocagem, a da retenção e a da reativação; assim, espera-se que ocorra uma reativação das representações no momento em que estas são solicitadas em uma interação social. Mas como reativar algo que não foi retido? Como ativar o modelo episódico de viagem de avião, se nunca se viajou de avião? Afinal, os estudos a respeito dos modelos cognitivos deixam claro que eles só surgem a partir de conhecimentos socioculturalmente determinados e vivencialmente adquiridos. Assim, para uma pessoa ser capaz de reativar um modelo de viagem de avião, ou ela já viajou, ou possui esse conhecimento pelas informações que lhe são passadas sobre o assunto. 
O trabalho de leitura realizado com a crônica "A outra noite" de Rubem Braga evidenciou como o desconhecimento de saberes, que se acredita serem compartilhados, interferem na produção de sentidos.

\section{A ausência de sentido no conhecimento não partilhado}

Antes de seguir a exposição do trabalho realizado é conveniente enfatizar que os estudos sobre leitura - senão todos, a maioria - enfatizam que a produção de sentidos está relacionada à construção e reconstrução dos conhecimentos adquiridos, já que esses estão em constante transformação e dependem, muitas vezes, do ponto de vista para terem esse ou aquele valor.

Passa-se, então, a examinar a atividade de leitura da crônica "A outra noite". Primeiro foi solicitado aos alunos que fizessem a leitura silenciosa - deve-se explicar a preferência por esse tipo de leitura por ser ela a habitual na vida quotidiana, raramente solicita-se a alguém que faça uma leitura em voz alta, além disso, esse método proporciona melhor compreensão, pois permite o retorno da leitura, bem como, adaptase às características de leitura de cada um.

Após o término da leitura foram feitas perguntas oralmente a fim de se verificar o nível de compreensão do texto. Seguem algumas das questões propostas e as respostas consensuais da turma:

- Em que cidade mora o autor?

- Copacabana, responderam os alunos.

Ninguém afirma que é necessário ir ao Rio de Janeiro para saber que Copacabana é um bairro dessa cidade, pois em vários momentos, principalmente em novelas, são feitas referências aos bairros cariocas. No entanto, essa informação não estava explícita no texto, e os alunos desviaram-se das pistas que o sujeito-produtor deixou ao longo da crônica e produziram um sentido inadequado. Braga ( $1978: 72$ ):

Outro dia fui a São Paulo e resolvi voltar à noite, uma noite de vento sul e chuva, tanto lá como aqui. Quando vinha para casa de táxi, encontrei um amigo e o trouxe até Copacabana.

Os alunos, para produzirem o sentido adequado, teriam que reativar na memória as representações cognitivas do que é Copacabana e associá-las à cidade do Rio de Janeiro.

O que faltou para que os alunos produzissem esse sentido adequado?

Primeiro, eles deveriam ter internalizados os conceitos do que é bairro e cidade; segundo, saberem que Copacabana é um bairro da cidade do Rio de Janeiro e, por último, reativá-los na memória. Entretanto, ao reativarem os conceitos retidos, ficaram em uma leitura superficial, que valorizou o nome Copacabana, porque estava explícito no texto e, também, acompanhado das expressões: vinha para casa e trouxe até Copacabana, levando os alunos a acreditarem que a cidade onde mora o autor é Copacabana.

O que acontece, nesses casos, é que se trabalha com a certeza de que esses conceitos de cidade e de localização de bairros famosos são compartilhados por todos, mas, a resposta dos alunos deixa claro que a realidade desmente essa crença. Segue o próximo exemplo: 
- Que transporte o autor usou para voltar de São Paulo?

- Táxi, responderam eles.

Nessa questão, como está explícito o nome táxi no texto, e os alunos possuíam o modelo cognitivo de táxi como um meio de transporte, eles fizeram, novamente, uma leitura superficial do texto e encontram a resposta que os satisfizeram. No entanto, se esses leitores tivessem retido em suas memórias o modelo episódico de viagem de avião, a resposta poderia ser outra, afinal, o sujeito-produtor espalhou pelo texto várias pistas que se refere à vôo.

(...) e contei a ele que lá em cima, além das nuvens, estava um luar lindo, de lua cheia; e que as nuvens feias que cobriam a cidade eram vistas de cima, enluaradas, colchões de sonhos, alvas, uma paisagem irreal.

Nota-se que as expressões: lá em cima, as nuvens feias que cobriam a cidade, vistas de cima, foram rejeitadas pelos alunos como implícitos de viagem de avião, porque eles não tinham o saber partilhado referente ao assunto e, portanto, produziram o sentido a partir do que conheciam, isto é, do conhecimento de mundo que estava retido em suas memórias, ou seja, táxi é um meio de transporte e está escrito no texto, assim, o autor voltou para sua cidade de táxi. Eles, por desconhecerem o modelo episódico de viagem de avião, não inferiram o uso do táxi do aeroporto para a casa do sujeitoprodutor. anterior:

Assim, as próximas questões surgiram em virtude da resposta da questão

- Como estava a noite acima das nuvens?

A resposta variava em:

- Linda..., com luar..., com lua cheia..., perfeita...

- Como ele viu essa noite?

Nessa questão, eles ficaram em dúvida e perceberam que algo não se encaixava, que faltava coerência, foi aí que responderam com sentido adequado a questão a respeito do meio de transporte.

- Ele voltou de avião, gritaram entusiasmados.

Portanto, quando foi enfatizado a eles as pistas que estavam no texto, eles ativaram seus conhecimentos enciclopédicos e produziram sentido coerente com o texto. Segue a última questão:

- Por que o título é "A outra noite"?

- Ele quer a outra noite, responderam.

Os alunos não notaram que o texto se referia a duas noites, a noite que seria a chuvosa, e a outra noite que seria a enluarada acima das nuvens. Esse mal-entendido relaciona-se, justamente, à ausência do saber partilhado, tanto episódico como semântico, pois nesse caso, houve, também, o desconhecimento do significado do 
pronome indefinido outra, que remete, segundo Ferreira, ao que é ( $1986: 1240$ ) diverso do primeiro; diferente de pessoa ou coisa especificada. Logo, os alunos não notaram a descrição de duas noites no texto, porque o desconhecimento de saberes, que se acredita serem partilhados, fez com que o sentido do texto, ou seja, sua idéia central, a oposição entre a noite abaixo das nuvens e a noite acima das nuvens, não fosse construído pelos alunos, apesar de terem percebido o engano com o meio de transporte.

\title{
Considerações finais
}

O exemplo de sala de aula aqui ilustrado permite verificar a importância do conhecimento de mundo partilhado para a produção de sentidos e como o professor ao assumi-lo, erroneamente, como partilhado, pode levar o aluno a um sentido não autorizado pelo sujeito-produtor.

Assim, para que ocorra a compreensão o leitor/ouvinte deve não apenas ser capaz de decodificar o texto, mas também, ser preparado para o reconhecimento dos sentidos, pois para Geraldi (1997: 166), a leitura seria reconhecimento de sentidos $e$ não produção de sentidos.

Por isso, muitas vezes, os alunos sentem dificuldades para compreender descrições, fatos, pensamentos que são expressos nos textos, porque eles não reconhecem o referente mencionado pelo sujeito-produtor.

Logo, uma discussão, uma figura que anteceda a leitura de um novo texto ajuda a minimizar o problema, pois permite um primeiro contato com o significado, ou seja, o conhecimento de mundo passa a ser partilhado e as pistas espalhadas pelo sujeitoprodutor ao longo do texto tornam-se mais claras para serem seguidas, o que leva à construção adequada do sentido.

Outra estratégia e preceder o trabalho de leitura com pesquisas em grupo em sala de aula onde o professor supervisiona o estudo. Essas pesquisas, podem ser feitas em conjunto com os professores orientadores de sala de leitura e de informática, caso não haja na escola esses meios a biblioteca é um ótimo recurso. A aula de Português fica diferente e os alunos gostam da novidade e o que é mais importante ampliam o conhecimento de mundo.

\section{Referências bibliográficas}

BRAGA, R. 200 crônicas escolhidas. Rio de Janeiro: Record, 1978.

FERREIRA, A. B. de H. Novo Dicionário da Língua Portuguesa. 2.ed. Rio de Janeiro: Nova Fronteira, 1996.

GERALDI, J. W. Portos de Passagem. 4. ed. São Paulo: Martins Fontes, 1997.

GRICE, H. P. Logic and conversation. In: COLE, P. \& MORGAN, J.L. (orgs.). Syntax and Semantics: Speech Acts. New York: Academic Press, 1995. v. 3.

KOCH, I. G. V. Desvendando os segredos do texto. São Paulo: Cortez, 2002.

\begin{abstract}
This article focus on the knowledge of shared world, trying to show that, many times, students are not able to construct the right meaning of a text, because the references presented are not, as a matter of fact, shared. It is supported by the social cognitive interactive conception and also by analysis of reading activities made with students of the sixth year grade - Middle School - who presented difficulties associated to the awareness of knowledge that we assume shared. This
\end{abstract}


study proposes to use some previous strategies in order to facilitate the subsequent reading and, indeed, decrease this particular problem.

Keywords: Knowledge of shared world, production of meaning, lack of meaning. 